\title{
BMJ Open Retrospective cohort study of cancer incidence and mortality by HIV status in a Georgia, USA, prisoner cohort during the HAART era
}

\author{
Maria Zlotorzynska, ${ }^{1}$ Anne C Spaulding, ${ }^{1}$ Lauren C Messina, ${ }^{1}$ Daniella Coker, ${ }^{1}$ \\ Kevin Ward, ${ }^{1}$ Kirk Easley, ${ }^{1}$ Jacques Baillargeon, ${ }^{2}$ Pamela J Mink, ${ }^{1,3}$ \\ Edgar P Simard ${ }^{1}$
}

To cite: Zlotorzynska M, Spaulding AC, Messina LC, et al. Retrospective cohort study of cancer incidence and mortality by HIV status in a Georgia, USA, prisoner cohort during the HAART era. BMJ Open 2016;6:e009778. doi:10.1136/bmjopen-2015009778

- Prepublication history and additional material is available. To view please visit the journal (http://dx.doi.org/ 10.1136/bmjopen-2015009778).

Received 19 August 2015 Revised 2 December 2015 Accepted 17 December 2015

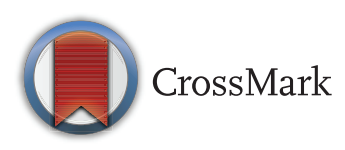

${ }^{1}$ Rollins School of Public Health, Emory University, Atlanta, Georgia, USA ${ }^{2}$ University of Texas Medical Branch, Galveston, Texas, USA

${ }^{3}$ Division of Applied

Research, Allina Health, Minneapolis, Minnesota, USA

Correspondence to Dr Anne C Spaulding; aspauld@emory.edu

\section{ABSTRACT}

Objective: Non-AIDS-defining cancers (NADCs) have emerged as significant contributors to cancer mortality and morbidity among persons living with HIV (PLWH). Because NADCs are also associated with many social and behavioural risk factors that underlie HIV, determining the extent to which each of these factors contributes to NADC risk is difficult. We examined cancer incidence and mortality among persons with a history of incarceration, because distributions of other cancer risk factors are likely similar between prisoners living with HIV and non-infected prisoners.

Design: Registry-based retrospective cohort study.

Participants: Cohort of 22422 persons incarcerated in Georgia, USA, prisons on 30 June 1991, and still alive in 1998.

Outcome measures: Cancer incidence and mortality were assessed between 1998 and 2009, using cancer and death registry data matched to prison administrative records. Age, race and sex-adjusted standardised mortality and incidence ratios, relative to the general population, were calculated for AIDSdefining cancers, viral-associated NADCs and noninfection-associated NADCs, stratified by HIV status.

Results: There were no significant differences in cancer mortality relative to the general population in the cohort, regardless of HIV status. In contrast, cancer incidence was elevated among the PLWH. Furthermore, incidence of viral-associated NADCs was significantly higher among PLWH versus those without HIV infection (standardised incidence ratio $=6.1,95 \%$ $\mathrm{Cl} 3.0$ to $11.7, p<0.001$ ).

Conclusions: Among PLWH with a history of incarceration, cancer incidence was elevated relative to the general population, likely related to increased prevalence of oncogenic viral co-infections. Cancer prevention and screening programmes within prisons may help to reduce the cancer burden in this high-risk population.

\section{INTRODUCTION}

In contrast to declining trends in incidence for the two major AIDS-defining cancers

\section{Strengths and limitations of this study}

- Persons living with HIV and HIV-uninfected members of the cohort both experienced a history of incarceration and likely have a similar distribution of cancer risk factors.

- The study design and long follow-up period emphasise long-term consequences of viral infection and exposure to alcohol and tobacco.

- Underestimation of associations with HIV infection is possible as we could not ascertain if those who tested HIV negative on prison entry later seroconverted to HIV.

(ADCs; Kaposi sarcoma and non-Hodgkin lymphoma), rates for some non-ADCs (NADCs) remain elevated or have increased over time for persons living with HIV (PLWH) despite widespread access since 1996 to highly active antiretroviral therapy (HAART). ${ }^{1}$ Although the causes of temporal increases for some NADCs are complex and multifactorial, an increased prevalence of lifestyle-related risk factors (eg, tobacco exposure) and the role of prolonged moderate levels of immune suppression among PLWH versus uninfected persons likely contribute to increased rates of NADCs. ${ }^{2-4}$ Studying cancer among prisoners with and without HIV offers an opportunity to assess the extent to which the heightened risk for malignancies is due to HIV infection itself versus the social and behavioural factors that underlie HIV infection. Regardless of HIV status, incarcerated persons often experience substance abuse, poverty and poor access to medical care prior to incarceration. ${ }^{5-7}$ Thus, among inmates, the distribution of important cancer risk factors may be similar between PLWH and non-infected persons. 
Numerous studies have found twofold to threefold elevated risk for NADCs among PLWH relative to the general population. ${ }^{8-10} \mathrm{~A}$ meta-analysis suggests that the cancer burden differs among those with and without HIV, with the former having excesses of infection-associated malignancies, notably Hodgkin lymphoma (Epstein-Barr virus, EBV), anal cancer (human papillomavirus, HPV), and liver cancer (hepatitis $\mathrm{B}$ and $\mathrm{C}$ viruses, $\mathrm{HBV}$ and $\mathrm{HCV}) \cdot{ }^{8-11}$ Lung cancer rates are also higher among PLWH. ${ }^{12}$ The reasons why the distribution of NADCs differs between PLWH and non-infected individuals are unclear, though some hypotheses exist. The increased prevalence of smoking among PLWH ${ }^{13}$ does not fully account for the observed elevated lung cancer incidence. ${ }^{12}{ }^{14}$ Persistent lung injury from pneumonias, prolonged immunosuppression, oxidative stress and HAART toxicity may contribute to lung tumorigenesis. ${ }^{10-12}$ Higher prevalence of co-infection with oncogenic viruses in some subgroups of HIV patients likely plays a role. For example, persistent anal HPV infections are high among men living with HIV who have sex with men, contributing to the observed increase in invasive anal cancer in this population. ${ }^{15}$ Similarly, liver cancer rates are elevated among PLWH with a history of injection drug use due to a high prevalence of chronic HBV and HCV infections. EBV is nearly ubiquitous among all US adults; however, among PLWH, Hodgkin lymphoma is a common NADC, perhaps due to changes in the immune system mediated by HAART. ${ }^{10} 16$

We previously conducted a retrospective cohort study of all-cause mortality in 23510 incarcerated men and women in the state of Georgia (GA) on 30 June 1991 by linking prison records with the National Death Index (NDI) in 2006. ${ }^{17}$ The study was recently updated to include deaths through 2010 and found $5 \%$ of the population were HIV infected and overall cancer was a close second to heart disease as a leading cause of death among all prisoners regardless of HIV status. ${ }^{6}$

The primary goal of the current study was to link the GA prisoner cohort from our previous study to the GA Comprehensive Cancer Registry (GCCR) database in order to ascertain cancer incidence data and to determine and compare cancer incidence patterns in PLWH and non-infected cohort members in the HAART era. Specifically, we sought to (1) characterise the distribution of incident cancers and cancer deaths among PLWH and uninfected cohort members; (2) compare the distribution of site-specific cancers in this cohort with the general GA population using standardised incidence ratios (SIRs) and standardised mortality ratios (SMRs); and (3) compare cancer incidence and mortality rates between the PLWH in the cohort and uninfected cohort members.

\section{METHODS}

Study population

As described in our prior studies, ${ }^{6}{ }^{17}$ the initial cohort consisted of all persons incarcerated in GA prisons on
30 June 1991. Administrative records containing demographic data and incarceration history were obtained from the GA Department of Corrections (GDC) Planning and Strategic Management Section and linked with the NDI through 31 December 2010. ${ }^{6}$ Participants could be either in prison, in the general population or alternating between both during the observational period. ${ }^{17}$ For the current analysis, we only considered those participants in the cohort who were alive on 1 January 1998. Between 30 June 1991 and 31 December 1997, a total of 1088 people died and 22422 remained alive. Although we had mortality information on the cohort since 1991, cancer incidence data were not available until 1998, which was well into the HAART era. We defined cause of death as the primary cause of death on the death certificate. We also removed from our analytic population 68 persons who did not identify as being 'black' or 'white' because we could not generate expected cancer or death counts for them. Therefore, follow-up for study outcomes in the current analysis began on 1 January 1998 and included 22354 people who were followed until 31 December 2010, cancer incidence or death.

The GDC administrative records contain the result of every HIV test performed during any prison stay. Using data from these records, participants were classified into two categories: ever HIV infected or no record of HIV positivity (hereafter referred to as HIV negative). The latter category includes those with missing HIV test results. Decedents were also classified as being persons who had lived with HIV for the entire study period if HIV was listed as the underlying or as a contributory cause of death on the death certificate. ADC assumes an HIV-infected status; when discussing these cancers in the HIV-negative population, we mean cancers of the same type as those that qualify as ADC.

\section{Statistical analysis}

The first aim was to characterise cancer incidence and mortality during 1998-2009 in the cohort of persons in prison on 30 June 1991. To ascertain incident cancer, administrative data on the cohort from the GDC were matched with the GCCR using probabilistic matching algorithms. Invasive cancers were categorised using the International Classification of Diseases for Oncology, third edition (ICD-O-3) codes $^{18}$ and only the first cancers were considered. Mortality was assessed through probabilistic matching with GCCR, and, for those with no matches in GCCR, a successive probabilistic matching with the NDI. Mortality data included the date of death and the ICD-9 or ICD-10 codes for the underlying and contributing causes of death. ${ }^{19} 20$

We first calculated the number of person-years of follow-up for the cohort, for PLWH and HIV-negative individuals. We also determined the frequency distributions of descriptive cohort characteristics including age in 1998, race, sex, educational level, pre-prison employment status, number of prison releases, vital status and 
cause of death, which were then stratified by HIV status. Finally, we calculated frequency distributions of stage at diagnosis for incident cancers, by HIV status and cancer type. SEER Summary Staging 1977 was used to stage cancers diagnosed between 1998 and 2000, SEER Summary Staging 2000 for cancers diagnosed between 2001 and 2003, and Collaborative Stage Derived Stage 2000 for cancers diagnosed in 2004 and later.

We used Pearson's $\chi^{2}$ test to assess associations of categorical variables and Student's t test for continuous variables.

The second aim was to compare the GA prisoner cohort to the GA general population with regard to cancer incidence and mortality. SMRs and SIRs (measures of risk relative to the general population) were calculated for all cancer types: ADCs (Kaposi sarcoma, non-Hodgkin lymphoma and cervical cancer), infection-associated NADC and non-infection-associated NADC. Infection-associated NADCs included a subset of NADCs with a known infectious cause: HPV-related anal and oropharyngeal cancer, HBV-related and/or HCV-related liver cancer and EBV-related Hodgkin lymphoma. ${ }^{921}$ All other cancers were considered not to be infection-related NADCs. SMRs were adjusted for age (in 5-year intervals), race, sex and year of death. Underlying population mortality rates in GA were determined using SEER*Stat software (http://seer.cancer. gov/seerstat) and were used to calculate expected death counts. SIRs were also adjusted for age (in 5-year intervals), race, sex and year of diagnosis. Underlying population cancer incidence rates (IRs) in GA were determined with SEER*Stat and were used to calculate expected count of incident cases. We only considered population rates as recorded in GA SEER registries (Atlanta Metropolitan and Rural GA in 1998 and 1999, and Atlanta Metro, Rural GA, and Greater GA from 2000 to 2009). In order to account for out-migration of the cohort from GA, we scaled the number of expected cases to the proportion of the cohort remaining in GA each year.

The third aim was to conduct an internal comparison of cancer incidence and mortality by HIV status. SMRs and SIRs were stratified by HIV status and corresponding 95\% CIs were calculated using the Poisson distribution. Both SIRs and SMRs were considered to be statistically significant if their 95\% CIs did not include the null value of 1.0. SIRs and SMRs and their 95\% CIs were calculated using exact methods. ${ }^{22} 23$ All analyses were conducted on de-identified data using SAS V.9.3 (Cary, North Carolina, USA). p Values $<0.05$ were considered statistically significant.

\section{RESULTS}

\section{Demographics}

Demographic characteristics by HIV status are presented in table 1. Among 22354 persons in the cohort remaining alive on 1 January 1998, there were $848(3.8 \%)$ who were classified as PLWH and 21506 as HIV negative. Incarcerated PLWH were more likely to be younger, black, female, less educated and have more releases during the study period. Among PLWH, 37.0\% died during the observation period versus $11.4 \%$ among HIV-negative people $(p<0.0001)$. HIV infection and cardiovascular disease were the leading cause of death for PLWH and those HIV negative, respectively.

\section{Characterising cancer within the prison cohort during 1998-2009}

Cancer incidence among study participants are presented by HIV status and cancer site (table 2). The incidence of all cancers combined (per 100000 personyears) was higher (IR=560.8, 95\% CI 419.5 to 735.4 ) among PLWH versus HIV-negative individuals (IR=303.5, 95\% CI 283.0 to 325.1; table 2). IRs for all ADCs, liver and anal cancer, and Hodgkin's lymphoma were higher among PLWH versus negative participants. Lung cancer was the most common incident NADC for PLWH and HIV-negative people. Rates of prostate cancer were higher among the HIV negative, a finding that has been previously observed. ${ }^{24} 25$ The IR per 100000 person-years of lung cancer among PLWH (91.6, 95\% CI 42.5 to 173.9$)$ exceeded that among the HIV-negative group (74.9, 95\% CI 65.0 to 85.9 ) but the 95\% CIs for the estimates overlapped (table 2). Stage at diagnosis of incident cancers (see online supplementary tables I-III) did not differ significantly by HIV status.

Study participants living with HIV experienced few cancer deaths $(\mathrm{N}=12$; table 3$)$. Lung cancer was the most common cause of cancer death among this group $(\mathrm{N}=5$; table 3). There was a single infection-associated NADC death: one participant died of hepatocellular carcinoma. Among HIV-negative participants, there were 481 cancer-related deaths. Lung ( $\mathrm{N}=195)$, colorectal $(\mathrm{N}=43)$ and hepatocellular cancer $(\mathrm{N}=28)$ predominated. Mortality rates for all causes of cancer deaths (table 3) did not differ significantly by HIV status.

\section{Comparing the prisoner cohort to the GA general population: an external comparison}

Among PLWH in the cohort, SIRs (a measure of relative risk, adjusted to the general population) were significantly greater than 1.0 for all cancers combined and for ADC, viral-associated NADC and lung cancer (table 4). Only the SIR for lung cancer $(1.5,95 \%$ CI 1.3 to 1.7$)$ was significantly higher than 1.0 for HIV-negative individuals.

All-cancer mortality was elevated for both prisoner groups (compared with the general population), although the SMR was only statistically significant for HIV-negative individuals (SMRs for both groups=1.2; table 5). The SMR for non-infection-related NADCs in PLWH was 1.4 , but the $95 \%$ CI was wide and included 1.0. No ADC deaths were observed among PLWH during the study period. HIV-negative individuals had 
Table 1 Selected demographic characteristics of 22354 inmates incarcerated in a Georgia state prison on 30 June 1991 and followed from 1 January 1998 until 31 December 2010, USA

\begin{tabular}{|c|c|c|c|c|c|}
\hline \multirow[b]{2}{*}{ Characteristic } & \multicolumn{2}{|c|}{$\begin{array}{l}\text { HIV infected } \\
(\mathrm{N}=848)^{*}\end{array}$} & \multicolumn{2}{|c|}{$\begin{array}{l}\text { HIV negative } \\
(\mathrm{N}=21506) \dagger\end{array}$} & \multirow[b]{2}{*}{ p Value } \\
\hline & $\mathbf{N}$ & Per cent & $\mathbf{N}$ & Per cent & \\
\hline \multicolumn{6}{|l|}{ Age in 1998 (years) } \\
\hline $20-29$ & 91 & 10.7 & 2547 & 11.8 & \\
\hline 30-39 & 439 & 51.8 & 9990 & 46.5 & \\
\hline $40-49$ & 274 & 32.3 & 6273 & 29.2 & \\
\hline$\geq 50$ & 44 & 5.2 & 2696 & 12.5 & \\
\hline Mean (SD) & $39(9)$ & & $38(7)$ & & $<0.0001 \ddagger$ \\
\hline Race/ethnicity & & & & & $<0.0001$ \\
\hline Black, non-Hispanic & 760 & 89.6 & 14047 & 65.3 & \\
\hline White, non-Hispanic & 88 & 10.4 & 7459 & 34.7 & \\
\hline Gender & & & & & 0.038 \\
\hline Male & 787 & 92.8 & 20318 & 94.5 & \\
\hline Female & 61 & 7.2 & 1188 & 5.5 & \\
\hline Education level in 1991 & & & & & $0.014 \S$ \\
\hline Less than high school & 516 & 60.9 & 12388 & 57.6 & \\
\hline High school or GED & 201 & 23.7 & 6127 & 28.5 & \\
\hline More than high school & 94 & 11.1 & 2214 & 10.3 & \\
\hline Unknown & 37 & 4.4 & 777 & 3.6 & \\
\hline \multicolumn{6}{|c|}{ Number of releases during observation period } \\
\hline 0 & 415 & 48.9 & 12469 & 58.0 & \\
\hline 1 & 277 & 32.7 & 6077 & 28.3 & \\
\hline 2 & 100 & 11.8 & 2086 & 9.7 & \\
\hline 3 & 44 & 5.2 & 669 & 3.1 & \\
\hline$\geq 4$ & 12 & 1.4 & 205 & 1.0 & \\
\hline Deceased at study end & & & & & $<0.0001$ \\
\hline Yes & 314 & 37.0 & 2457 & 11.4 & \\
\hline No & 534 & 63.0 & 19049 & 88.6 & \\
\hline \multicolumn{6}{|l|}{ Primary cause of death } \\
\hline HIV infection & 221 & 70.4 & 0 & 0 & \\
\hline Cardiovascular diseases & 23 & 7.3 & 691 & 28.1 & \\
\hline Cancer & 12 & 3.8 & 481 & 19.6 & \\
\hline Liver disease $e^{\star \star}$ & 7 & 2.2 & 163 & 6.6 & \\
\hline Homicide & 6 & 1.9 & 142 & 5.8 & \\
\hline Other & 45 & 14.4 & 980 & 39.9 & \\
\hline
\end{tabular}

*Includes 792 who were HIV infected and 56 who had HIV infection as a cause of death.

tIncludes 20474 who were HIV negative, 15 who had an indeterminate result and 1017 unknown.

łt test.

$\S$ Calculation excludes those with unknown education level. The $p$ value including those with unknown status is 0.02 .

TData available through 2 September 2010.

${ }^{\star *}$ Excludes liver cancer.

GED, general educational development.

significantly higher all-cause mortality and cancer mortality, except from ADC, as compared with the reference population.

\section{An indirect, internal comparison of cancer incidence and} mortality ratios by HIV status

SIRs (table 4) for all cancers combined (2.3, 95\% CI 1.7 to 3.0 ) and viral-associated NADCs $(6.1,95 \%$ CI 3.0 to $11.7)$ were both significantly elevated $(p<0.001$ for each) among PLWH versus negative individuals. CIs for the SIRs for non-viral associated ADCs between the PLWH and HIV negative overlapped.

Table 5 illustrates that all-cause mortality was higher among PLWH versus negative participants $(\mathrm{SMR}=4.3$,
95\% CI 3.8 to $4.9, \mathrm{p}<0.001)$. However, the SMRs for all cancers, and cancers by type, did not significantly differ.

\section{DISCUSSION}

In this exploratory pilot study of a cohort incarcerated two decades ago, we found that incident cancers were common among both PLWH and non-infected members of the cohort imprisoned on 30 June 1991. During the HAART era, rates of viral-associated NADCs were about six times higher than expected among PLWH relative to the general population, highlighting a higher prevalence of oncogenic viral co-infections and perhaps poorer overall health status. Regarding cancer mortality, 
Table 2 Unadjusted cancer incidence, per 100000 PY, by site and HIV status

\begin{tabular}{|c|c|c|c|c|}
\hline & \multicolumn{2}{|c|}{ HIV infected } & \multicolumn{2}{|c|}{ HIV negative } \\
\hline & $\mathbf{N}$ & Incidence per 100000 PY (95\% CI) & $\overline{\mathbf{N}}$ & Incidence per 100000 PY (95\% Cl) \\
\hline All cancers & 49 & $560.8(419.5$ to 735.4$)$ & 798 & 303.5 (283.0 to 325.1$)$ \\
\hline ADC & 16 & 183.1 (108.4 to 291.0$)$ & 29 & $11.0(7.5$ to 15.6$)$ \\
\hline Non-Hodgkin lymphoma & 13 & $148.8(82.8$ to 248.1$)$ & 28 & 10.6 (7.2 to 15.2$)$ \\
\hline Kaposi sarcoma & 2 & 22.9 (3.8 to 75.6$)$ & 0 & - \\
\hline Cervix & 1 & $11.4(0.6$ to 56.4$)$ & 1 & $0.4(0.02$ to 1.9$)$ \\
\hline Viral-related NADC & 10 & 114.5 (58.1 to 204.0$)$ & 54 & 20.5 (15.6 to 26.6$)$ \\
\hline Liver & 4 & 45.8 (14.6 to 110.4$)$ & 25 & $9.5(6.3$ to 13.8$)$ \\
\hline HPV-related oral* & 1 & $11.4(0.6$ to 56.4$)$ & 18 & 6.8 (4.2 to 10.6$)$ \\
\hline Anal & 2 & 22.9 (3.8 to 75.6$)$ & 2 & $0.8(0.1$ to 2.5$)$ \\
\hline Hodgkin lymphoma & 3 & 34.3 (8.7 to 93.5$)$ & 8 & $3.0(1.4$ to 5.8$)$ \\
\hline Penis & 0 & - & 1 & $0.4(0.02$ to 1.9$)$ \\
\hline Non-viral-related NADC & 23 & 263.2 (170.9 to 388.8 ) & 715 & 271.9 (252.5 to 292.4$)$ \\
\hline Lung and bronchus & 8 & 91.6 (42.5 to 173.9$)$ & 197 & 74.9 (65.0 to 85.9$)$ \\
\hline Prostate & 1 & $11.4(0.6$ to 56.4$)$ & 165 & 62.7 (53.7 to 72.9$)$ \\
\hline Colorectal & 5 & $57.2(21.0$ to 126.9$)$ & 82 & $31.2(25.0$ to 38.5$)$ \\
\hline Kidney and renal pelvis & 2 & $22.9(3.8$ to 75.6$)$ & 34 & $12.9(9.1$ to 17.9$)$ \\
\hline Stomach & 1 & $11.4(0.6$ to 56.4$)$ & 18 & 6.8 (4.2 to 10.6$)$ \\
\hline Other & 6 & 68.7 (27.8 to 142.8$)$ & 205 & 78.0 (67.8 to 89.2$)$ \\
\hline
\end{tabular}

${ }^{*}$ Oropharynx, tonsil, tongue (squamous cell).

ADC, AIDS-defining cancer; NADC, non-ADC; PY, person-years.

there were few cancer deaths among the PLWH in the cohort hampering our ability to draw strong conclusions regarding differences by HIV status among people with a history of incarceration. Nonetheless, there was a suggestion that liver cancer deaths may be elevated in this population. Though we did not have data on the prevalence of $\mathrm{HBV}$ and $\mathrm{HCV}$ infection in this population, as GA prisons do not conduct routine screening for these viruses, previous studies of incarcerated populations have found that seroprevalence of these infections is high. $^{26} 27$ Similar to studies of PLWH in the general population, PLWH with a history of incarceration are at elevated risk for some cancers, which warrants public health interventions.

The pattern of incident cancers among PLWH in our study differs somewhat from among PLWH observed previously. Similar to a large nationally representative study, we found that non-Hodgkin lymphoma was the most

Table 3 Unadjusted all-cause and cancer mortality rates, per 100000 PY, by site and HIV status

\begin{tabular}{|c|c|c|c|c|}
\hline & \multicolumn{2}{|c|}{ HIV infected } & \multicolumn{2}{|c|}{ HIV negative } \\
\hline & $\mathbf{N}$ & Incidence per 100000 PY (95\% Cl) & $\mathbf{N}$ & Incidence per 100000 PY $(95 \% \mathrm{Cl})$ \\
\hline All-cause mortality & 314 & 3560.1 (3182.4 to 3970.7$)$ & 2457 & 926.5 (890.5 to 963.7$)$ \\
\hline All cancers & 12 & 136.1 (73.7 to 231.3$)$ & 481 & $181.4(165.7$ to 198.2$)$ \\
\hline ADC & 0 & - & 12 & $4.5(2.5$ to 7.7$)$ \\
\hline Non-Hodgkin lymphoma & 0 & - & 12 & 4.5 (2.5 to 7.7$)$ \\
\hline Kaposi sarcoma & 0 & - & 0 & - \\
\hline Cervix & 0 & - & 0 & - \\
\hline Viral-related NADC & 1 & $11.3(0.6$ to 55.9$)$ & 35 & 13.2 (9.3 to 18.2$)$ \\
\hline Liver & 1 & $11.3(0.6$ to 55.9$)$ & 28 & 10.6 to 15.1$)$ \\
\hline HPV-related oral* & 0 & - & 5 & $1.9(0.7$ to 4.2$)$ \\
\hline Anal & 0 & - & 2 & 0.8 (0.1 to 2.5$)$ \\
\hline Hodgkin lymphoma & 0 & - & 0 & - \\
\hline Penis & 0 & - & 0 & - \\
\hline Non-viral-related NADC & 11 & 124.7 (65.6 to 216.8$)$ & 434 & $163.7(148.8$ to 179.6$)$ \\
\hline Lung and bronchus & 5 & 56.7 (20.8 to 125.7$)$ & 195 & 73.5 (63.7 to 84.4$)$ \\
\hline Prostate & 0 & - & 21 & 7.9 (5.0 to 11.9$)$ \\
\hline Colorectal & 2 & 22.7 (3.8 to 74.9 ) & 43 & 16.2 (11.9 to 21.6$)$ \\
\hline Kidney and renal pelvis & 0 & - & 15 & 5.7 (3.3 to 9.1$)$ \\
\hline Stomach & 0 & - & 16 & 6.0 (3.6 to 9.6$)$ \\
\hline Other & 4 & 45.4 (14.4 to 109.4$)$ & 124 & 46.8 to 55.6$)$ \\
\hline
\end{tabular}


Table 4 SIRs* in a prisoner cohort, by subtypes of cancers and HIV status

\begin{tabular}{|c|c|c|c|c|c|c|c|c|}
\hline & \multicolumn{3}{|c|}{ HIV infected } & \multicolumn{5}{|c|}{ HIV negative } \\
\hline & Observed & Expected & SIR (95\% CI) & Observed & Expected & SIR (95\% CI) & SIR (95\% Cl) & p Valuet \\
\hline All cancers & 49 & 26 & 2.0 (1.5 to 2.6$)$ & 798 & 928 & 0.9 (0.8 to 0.9$)$ & 2.3 (1.7 to 3.0$)$ & $<0.001$ \\
\hline ADC & 16 & 2 & 8.0 (4.6 to 13.0$)$ & 29 & 53 & $0.6(0.4$ to 0.8$)$ & 14.6 (7.8 to 26.8$)$ & $<0.001$ \\
\hline NADC & 33 & 24 & $1.4(0.9$ to 1.9$)$ & 769 & 916 & 0.8 (0.8 to 0.9$)$ & 1.6 (1.1 to 2.3$)$ & 0.009 \\
\hline Viral-associated & 10 & 2 & 6.3 (3.0 to 11.5$)$ & 54 & 53 & $1.0(0.8$ to 1.3$)$ & 6.1 (3.0 to 11.7$)$ & $<0.001$ \\
\hline Non-viral-associated & 23 & 23 & $1.0(0.6$ to 1.5$)$ & 715 & 863 & $0.8(0.8$ to 0.9$)$ & $1.2(0.8$ to 1.8$)$ & 0.37 \\
\hline Lung and bronchus & 8 & 3 & 2.7 (1.2 to 5.3$)$ & 197 & 134 & 1.5 (1.3 to 1.7$)$ & $1.8(0.8$ to 3.5$)$ & 0.12 \\
\hline Colorectal & 5 & 3 & 1.7 (0.5 to 3.9$)$ & 82 & 98 & 0.8 (0.7 to 1.04$)$ & $2.0(0.7$ to 4.6$)$ & 0.16 \\
\hline
\end{tabular}

95\% Cls for SIR were estimated using exact methods based on the Poisson distribution. Exact methods were used to compare two SIRs (Brownlee, ${ }^{22}$ p. 184 and WHO ${ }^{23}$ ).

*SIRs adjusted for age (in 5-year intervals), race, sex and year of diagnosis.

tp Value is for SIR difference.

ADC, AIDS-defining cancer; NADC, non-ADC; SIR, standardised incidence ratio.

Table 5 SMRs* in a prisoner cohort, by subtypes of cancers and HIV status

\begin{tabular}{|c|c|c|c|c|c|c|c|c|}
\hline & \multicolumn{3}{|c|}{ HIV infected } & \multicolumn{3}{|c|}{ HIV negative } & \multirow[b]{2}{*}{ SMR (95\% Cl) } & \multirow[b]{2}{*}{ p Value } \\
\hline & Observed & Expected & SMR (95\% Cl) & Observed & Expected & SMR (95\% CI) & & \\
\hline All causes & 314 & 55 & 5.7 (5.1 to 6.4$)$ & 2457 & 1863 & 1.3 (1.3 to 1.4$)$ & 4.3 (3.8 to 4.9 ) & $<0.001$ \\
\hline All cancers & 12 & 10 & $1.2(0.6$ to 2.1$)$ & 481 & 394 & $1.2(1.1$ to 1.3$)$ & $1.0(0.5$ to 1.7$)$ & 0.99 \\
\hline ADC & 0 & 0.3 & - & 12 & 13 & $0.9(0.5$ to 1.6$)$ & - & - \\
\hline NADC & 12 & 10 & $1.2(0.6$ to 2.1$)$ & 469 & 381 & $1.2(1.1$ to 1.4$)$ & $1.1(0.6$ to 1.8$)$ & 0.81 \\
\hline Viral-associated & 1 & 0.7 & $1.4(0.04$ to 8.0$)$ & 35 & 23 & 1.5 (1.1 to 2.1$)$ & $0.9(0.05$ to 4.9$)$ & 1.00 \\
\hline Non-viral-associated & 11 & 9 & $1.2(0.6$ to 2.2$)$ & 434 & 358 & $1.2(1.1$ to 1.3$)$ & $1.01(0.5$ to 1.8$)$ & 0.94 \\
\hline Lung and bronchus & 5 & 3 & 1.7 (0.5 to 3.9$)$ & 195 & 121 & 1.6 (1.4 to 1.9$)$ & 1.03 (0.4 to 2.3$)$ & 0.89 \\
\hline Colorectal & 2 & 1 & $2.0(0.2$ to 7.2$)$ & 43 & 40 & $1.1(0.8$ to 1.5$)$ & 1.9 (0.3 to 6.5) & 0.40 \\
\hline
\end{tabular}

$95 \%$ Cls for SMR were estimated using exact methods based on the Poisson distribution. Exact methods were used to compare two SMRs (Brownlee, ${ }^{22} \mathrm{p.} .184$ and WHO ${ }^{23}$ ).

*SMRs were adjusted for age (in 5-year intervals), race, sex and year of death.

tp Value is for SMR difference.

ADC, AIDS-defining cancer; NADC, non-ADC; SMR, standardised mortality ratio. 
common ADC. ${ }^{28}$ However, among PLWH with a history of incarceration, we noted lung, colon and liver cancers as the most common NADCs versus lung, anal and prostate cancers in the general HIV population. ${ }^{13}$ Reasons for fewer anal cancers diagnosed in the cohort are unclear-whether participants have lower risk versus risk undisclosed to their healthcare providers and thus less frequent screening. The paucity of prostate cancers may stem from this being a relatively young population. Nonetheless, the elevated SIRs among PLWH in our study for ADCs and NADCs (particularly viral-associated NADCs) are important areas for prevention and future research.

Relative to the general population, all-cause mortality, but not cancer mortality, was significantly elevated among PLWH versus HIV-negative participants with a history of incarceration. Perhaps this reflects an even playing field between PLWH and HIV-negative patients with cancer with regard to mortality. Conversely, the follow-up period may have been insufficient for incident cancers to have progressed into fatal disease. It is also possible that HIV-related mortality presented a competing risk for this group, thus attenuating the rate of cancer mortality. Our analyses of cancer mortality were likely underpowered due to the small number of observed cancer deaths among PLWH with a history of incarceration, although the point estimates for all cancers combined $(\mathrm{SMR}=1.2)$ suggested an increased risk of cancer death. Two recent studies suggest that cancer treatment rates are lower among people with HIV/AIDS, which likely contributes to this disparity. ${ }^{29} 30$ Elevated all-cause mortality among PLWH relative to the general population may be due in part to inadequate control of HIV-related disease, underscoring the need for programmes that retain PLWH in the HIV care system after release. ${ }^{31-33}$

Although most prison systems lack adequate resources to expand cancer screening and prevention programmes, courts have ruled that they cannot have deliberate indifference to previously existing or newly diagnosed medical conditions. HIV viral suppressionwhich is associated with increased survival time and a decreased risk of some ADCs and NADCs-should be a focus for prisoners living with HIV. ${ }^{34}$ Additionally, treatment and screening for HBV and HCV, which decrease the risk of hepatocellular carcinoma, are important components of correctional healthcare systems. Finally, smoking is associated with a number of cancers, and tobacco cessation reduces the risk of lung and other tobacco-associated malignancies. A prison record may hinder employment and thus health insurance, resulting in decreased access to healthcare. Lack of insurance ${ }^{36} 37$ and diminished lifetime earning power, ${ }^{38}$ estimated $10-30 \%$ less among people with a history of incarceration, ${ }^{39} 40$ may increase risk of several cancer types as well as adversely impact treatment and survival. In addition, exposure to known carcinogens is high among prisoners: $65.7 \%$ and $85.4 \%$ are smokers and alcohol users, respectively, and risk of cancer is higher than age, gender, race, socioeconomic controls; only when further adjusting for smoking does the risk of cancer become equivalent to the non-incarcerated. ${ }^{41}$

This study has several strengths. Persons in the HIV-infected and HIV-uninfected arms had some characteristics in common, most notably incarceration. PLWH were more likely to be black and less educated, factors associated with poorer overall, HIV and cancerspecific survival; on the other hand, they were younger and more likely female, factors that are normally protective. Nonetheless, if they were not matched by socioeconomic status in 1991, releasees in both arms had to contend with similar barriers to healthcare. Additionally, by studying a cohort formed by taking a cross-section of persons dwelling in prison, rather than a cohort of releasees, we de-emphasise immediate deaths, including cancer deaths. Instead, the methodology highlights long-term sequelae of exposure to toxins such as alcohol and tobacco, and viruses such as $\mathrm{HBV}$ and $\mathrm{HCV}^{6}$

Our study also has limitations, such as possible ascertainment bias. We did not have access to HIV status apart from the prison records and death data. Some persons classified as HIV negative based on prison entry testing may have later seroconverted to HIV, therefore underestimating observed associations with HIV infection. Causes of mortality were obtained from prisoners' and releasees' death certificates, which are filled out either by physicians or county coroners. Unlike many other states, GA does not mandate autopsy for deaths in custody, which could potentially introduce misclassification of cause of death, although any such misclassification would be independent of HIV infection. We were also unable to obtain information on smoking status, HAART adherence, cancer treatment and markers of HIV severity (eg, CD4 count, viral load). Finally, because we defined our cohort based on incarceration in 1991 but began follow-up in 1998, survival bias may have been introduced. All of these factors may reduce generalisability.

In conclusion, this descriptive study found elevated cancer incidence among PLWH with a history of incarceration relative to the general population. These results underscore the need for cancer prevention and control programmes within prisons and to ensure releasees also have access to a medical home with follow-up appointments and regular cancer screening. Longer study of this cohort is warranted to assess whether an excess of cancer mortality will eventually be observed and if that will differ by HIV status. Expanding such registry linkage studies to other states with larger incarcerated HIV populations will further inform correctional and public health policy in the USA.

Acknowledgements The authors thank Timothy S Carr, PhD, of the Georgia Department of Corrections for his assistance with procuring inmate records and Elizabeth Fox-Mtandika, MPH, for her assistance with manuscript preparation. 
Contributors ACS, PJM, KW and EPS conceived and planned the study. MZ, LCM and KE performed the statistical analyses. MZ, ACS, LCM, DC, JB and EPS contributed to writing the paper and prepared the manuscript. KE, JB and PJM made critical edits to the manuscript. All authors reviewed and approved the final version.

Funding This research was funded by Emory Center for AIDS Research (P30 Al050409) under a supplement from the National Institute of Allergy and Infectious Diseases Center for AIDS Research—National Cancer Institute.

Competing interests ACS reports grants and personal fees from Gilead Sciences, during the conduct of the study; personal fees from Janssen, grants from Boehringer Ingelheim, grants from Bristol Myers Squibb, outside the submitted work.

Ethics approval This study was approved by the Georgia Department of Public Health and the Emory University Institutional Review Board.

Provenance and peer review Not commissioned; externally peer reviewed.

Data sharing statement No additional data are available.

Open Access This is an Open Access article distributed in accordance with the Creative Commons Attribution Non Commercial (CC BY-NC 4.0) license, which permits others to distribute, remix, adapt, build upon this work noncommercially, and license their derivative works on different terms, provided the original work is properly cited and the use is non-commercial. See: http:// creativecommons.org/licenses/by-nc/4.0/

\section{REFERENCES}

1. Engels EA, Pfeiffer RM, Goedert JJ, et al. Trends in cancer risk among people with AIDS in the United States 1980-2002. AIDS 2006;20:1645-54.

2. Engels EA, Brock MV, Chen J, et al. Elevated incidence of lung cancer among HIV-infected individuals. J Clin Oncol 2006;24:1383-8.

3. Bertisch B, Franceschi S, Lise M, et al. Risk factors for anal cancer in persons infected with HIV: a nested case-control study in the Swiss HIV Cohort Study. Am J Epidemiol 2013;178:877-84.

4. Engels EA, Madeleine MM. Invited commentary: biological and clinical insights from epidemiologic research into HIV, HPV, and anal cancer. Am J Epidemiol 2013;178:885-7.

5. Westergaard RP, Spaulding AC, Flanigan TP. HIV among persons incarcerated in the USA: a review of evolving concepts in testing treatment, and linkage to community care. Curr Opin Infect Dis 2013;26:10-16.

6. Spaulding AC, Sharma A, Messina LC, et al. A comparison of liver disease mortality with HIV and overdose mortality among Georgia prisoners and releasees: a 2-decade cohort study of prisoners incarcerated in 1991. Am J Public Health 2015;105:e51-7.

7. Freudenberg N. Jails, prisons, and the health of urban populations: a review of the impact of the correctional system on community health. J Urban Health 2001;78:214-35.

8. Engels EA, Biggar RJ, Hall HI, et al. Cancer risk in people infected with human immunodeficiency virus in the United States. Int $J$ Cancer 2008:123:187-94.

9. Silverberg MJ, Chao C, Leyden WA, et al. HIV infection and the risk of cancers with and without a known infectious cause. AIDS 2009;23:2337-45

10. Franceschi S, Lise M, Clifford GM, et al. Changing patterns of cancer incidence in the early- and late-HAART periods: the Swiss HIV Cohort Study. Br J Cancer 2010;103:416-22.

11. Shiels MS, Cole SR, Kirk GD, et al. A meta-analysis of the incidence of non-AIDS cancers in HIV-infected individuals. J Acquir Immune Defic Syndr 2009;52:611-22.

12. Chaturvedi AK, Pfeiffer RM, Chang L, et al. Elevated risk of lung cancer among people with AIDS. AIDS 2007;21:207-13.

13. Tesoriero JM, Gieryic SM, Carrascal A, et al. Smoking among HIV positive New Yorkers: prevalence, frequency, and opportunities for cessation. AIDS Behav 2010;14:824-35.

14. Giordano TP, Kramer JR. Does HIV infection independently increase the incidence of lung cancer? Clin Infect Dis 2005;40:490-1.

15. Silverberg MJ, Lau B, Justice AC, et al. Risk of anal cancer in HIV-infected and HIV-uninfected individuals in North America. Clin Infect Dis 2012:54:1026-34.
16. Biggar RJ, Jaffe ES, Goedert JJ, et al. Hodgkin lymphoma and immunodeficiency in persons with HIV/AIDS. Blood 2006;108: 3786-91.

17. Spaulding AC, Seals RM, McCallum VA, et al. Prisoner survival inside and outside of the institution: implications for health-care planning. Am J Epidemiol 2011;173:479-87.

18. Fritz AG. International Classification of Diseases for Oncology: $I C D-O$. 3rd edn. Geneva, Switzerland: World Health Organization, 2000.

19. World Health Organization. Manual of the International Statistical Classification of Diseases, Injuries, and Causes of Death. 9th Rev. Geneva, Switzerland: World Health Organization, 1977.

20. World Health Organization. Manual of the International Statistical Classification of Diseases, Injuries, and Causes of Death. 10th Rev. 2nd edn. Geneva, Switzerland: World Health Organization, 2004.

21. de Martel C, Ferlay J, Franceschi S, et al. Global burden of cancers attributable to infections in 2008: a review and synthetic analysis. Lancet Oncol 2012;13:607-15.

22. Brownlee K. Statistical theory and methodology in science and engineering. 2nd edn. New York: John Wiley, 1965.

23. World Health Organization. Statistical Methods in Cancer Research - Volume II-The Design and Analysis of Cohort Studies: Comparison of standardized mortality ratios. http://www.iarc.fr/en/ publications/pdfs-online/stat/sp82/SP82_vol2-3.pdf (accessed $20 \mathrm{Ju}$ 2015).

24. Marcus JL, Chao CR, Leyden WA, et al. Prostate cancer incidence and prostate-specific antigen testing among HIV-positive and HIV-negative men. J Acquir Immune Defic Syndr 2014;66:495-502.

25. Silverberg MJ, Chao C, Leyden WA, et al. HIV infection, immunodeficiency, viral replication, and the risk of cancer. Cancer Epidemiol Biomarkers Prev 2011;20:2551-9.

26. Khan AJ, Simard EP, Bower WA, et al. Ongoing transmission of hepatitis $B$ virus infection among inmates at a state correctional facility. Am J Public Health 2005;95:1793-9.

27. Varan AK, Mercer DW, Stein MS, et al. Hepatitis C seroprevalence among prison inmates since 2001: still high but declining. Public Health Rep 2014:129:187-95.

28. Shiels MS, Pfeiffer RM, Gail MH, et al. Cancer burden in the HIV-infected population in the United States. J Natl Cancer Inst 2011;103:753-62.

29. Suneja G, Shiels MS, Melville SK, et al. Disparities in the treatment and outcomes of lung cancer among HIV-infected individuals. AIDS 2013;27:459-68.

30. Suneja G, Shiels MS, Angulo R, et al. Cancer treatment disparities in HIV-infected individuals in the United States. J Clin Oncol 2014;32:2344-50.

31. Springer SA, Pesanti E, Hodges J, et al. Effectiveness of antiretroviral therapy among HIV-infected prisoners: reincarceration and the lack of sustained benefit after release to the community. Clin Infect Dis 2004;38:1754-60.

32. Springer SA, Spaulding AC, Meyer JP, et al. Public health implications for adequate transitional care for HIV-infected prisoners: five essential components. Clin Infect Dis 2011;53:469-79.

33. Estelle v. Gamble, U.S. Supreme Court 1976:97.

34. Biggar RJ, Chaturvedi AK, Goedert JJ, et al. AIDS-related cancer and severity of immunosuppression in persons with AIDS. J Natl Cancer Inst 2007;99:962-72.

35. Simard EP, Pfeiffer RM, Engels EA. Spectrum of cancer risk late after AIDS onset in the United States. Arch Intern Med 2010;170:1337-45.

36. Halpern MT, Ward EM, Pavluck AL, et al. Association of insurance status and ethnicity with cancer stage at diagnosis for 12 cancer sites: a retrospective analysis. Lancet Oncol 2008;9:222-31.

37. Ward E, Halpern M, Schrag N, et al. Association of insurance with cancer care utilization and outcomes. CA Cancer J Clin 2008;58:9-31.

38. Gorey KM, Vena JE. The association of near poverty status with cancer incidence among black and white adults. $J$ Community Health 1995;20:359-66.

39. Western B, Kling JR, Weiman DF. The labor market consequences of incarceration. Crime Delinquency 2001;47:410-27.

40. Petersilia J. When prisoners come home: parole and prisoner reentry. New York City: Oxford University Press, 2003.

41. Binswanger IA, Krueger PM, Steiner JF. Prevalence of chronic medical conditions among jail and prison inmates in the USA compared with the general population. J Epidemiol Community Health 2009;63:912-19. 